\title{
SITES OF WATER EXCHANGE BETWEEN THE MATERNAL SYSTEM AND THE AMNIOTIC FLUID OF RABBITS ${ }^{1}$
}

\author{
By WILLIAM M. PAUL,2 THEODORE ENNS, SAMUEL R. M. REYNOLDS, AND \\ FRANCIS P. CHINARD \\ (From The Department of Embryology, The Carnegie Institution of Washington, The De- \\ partments of Medicine and Physiological Chemistry, The Johns Hopkins University \\ School of Medicine, and The Medical Division, Baltimore City Hospitals, \\ Baltimore, $M d$.)
}

(Submitted for publication August 10, 1955 ; accepted February 9, 1956)

It is well established that there is rapid exchange of water between the maternal circulation and the amniotic fluid in the guinea pig and the human (1-4). It has been suggested that amniotic fluid may be formed, partly or entirely, by the amnion (5), by the fetal kidney $(6,7)$, by the fetal lung $(8,9)$ and in the buccal and nasal cavities (10). It has been implied that the calculated rates of exchange of water represent real volumes of water crossing the barriers and that the sites of formation and of removal of amniotic fluid are not necessarily the same (7). Some of these suggestions and concepts would lead to the hypothesis that water entered the amniotic fluid by way of the placenta and the fetus and left by way of some other route, possibly across the fetal membranes; the system as a whole would then be a series one for water with "feed-back" from the amniotic fluid to the maternal system. Maintenance of the relative constancy of volume of the amniotic fluid would be the result of a steady state rather than of equilibrium with respect to water between amniotic and maternal fluids. ${ }^{3}$

Apparently, no consideration has been given to

1 Supported by grants from the Life Insurance Medical Research Fund, by a contract, AT (30-1)-1394, between the U. S. Atomic Energy Commission and the Johns Hopkins University and by the Veterans Administration, Contract V1001M-527, with the advice of the Committee on Veterans Medical Problems of the National Research Council.

2 Travelling Fellow, The R. Samuel McLaughlin Foundation. Present address: Dept. of Obstetrics and Gynecology, University of Toronto, Toronto, Canada.

8 In a steady state, constancy of volume is maintained by equality of influx and efflux of water. Under equilibrium conditions (with respect to water) the chemical potentials of water in the two compartments or systems are equal and there is no net passage of water in or out though exchange of water molecules may occur at a rapid rate. the possibility that water molecules might exchange across two independent barrier systems or sites: 1) the fetus-placenta complex and 2) the membranes. ${ }^{4}$ Under such circumstances a close approach to equilibrium with respect to water could obtain between the maternal system and amniotic fluid; the slow changes of volume of amniotic fluid during gestation would be the result of a very small inequality of the high rates of exchange in and out of amniotic fluid. There would then be exchange of water between amniotic fluid and maternal blood, the maternal blood and the fetus, and the fetus and amniotic fluid.

In the present studies an attempt has been made to assess the relative importance of the fetal membranes and of the fetus-placenta complex in the exchange of water between the maternal and amniotic fluids. To this end the time course has been determined of the distribution between maternal blood and amniotic fluid of deuterium oxide injected into the maternal circulation and of tritium oxide simultaneously injected into the amniotic fluid; this has been done in the intact system, with the vitelline vessels ligated, and with the fetus killed. The deuterium data are used to characterize the rate of passage of water molecules from the maternal system to the amniotic fluid and the tritium data are used to characterize the rate of passage of water molecules in the opposite direction. With the fetal system intact, equality of the rates would permit no deductions as to the site or sites of passage. However, in the event the steady-state series hypothesis were correct, killing the fetus would interrupt the continuity of the system and should result in a disproportionately

\footnotetext{
4 Brambell (11) has shown that passive immunization of the fetus in utero may occur by passage of antibody proteins across the membranes.
} 
large reduction of the rate of influx of deuterium oxide compared to the rate of efflux of tritium oxide. If, however, the equilibrium exchange hypothesis were correct, killing the fetus would result in an equal reduction of both rates and this reduction would be a measure of the contribution of the fetus-placenta complex to the exchanges. As shown below, the latter of the two hypotheses fits the facts.

\section{METHODS AND PROCEDURE}

\section{Operative and experimental procedure}

Albino rabbits of weights between 2,800 and 4,600 grams, at the 24th day of gestation (i.e., at a period of maximum fluid accumulation [12]), anesthetized with diallylbarbituric acid, were used as experimental animals. The experimental procedure was based on the following anatomical relationships. The amnion is bloodless and is supported by the yolk-sac splanchnopleure which in turn lies adjacent to the decidua of the uterine wall. The yolk sac splanchnopleure corresponds in position to the chorionic membrane of the human. The fetal membranes have two distinct blood supplies. The first is of maternal origin by way of the decidual arteries. The second is of fetal origin by way of branches of the umbilical vessels; these branches course between the amnion and the yolk sac splanchnopleure (Figure 1). These fetal vessels are readily visualized through the uterine wall as they spread over the membranes. By means of the technique described by Brambell, Hemmings, Hemmings, Henderson, and Rowlands (13) the main stems of the vessels were isolated through a 2 to $3 \mathrm{~mm}$. incision in the uterus, ligated and returned to the uterine lumen without injury to the underlying amnion. This procedure eliminates the fetal blood supply to the membranes and leaves only the maternal vessels to supply these; the fetus and the placental circulation remain intact.

Three basic preparations were used in these studies. In the first (Figure 1a), the conceptus was untouched. In the second (Figure 1b), the fetal blood supply to the membranes was interrupted as described. In the third (Figure 1c), the fetus was killed by crushing the pressure through the uterine wall without visible evidence of damage to the underlying membranes. Accordingly, in the first preparation the fetal and maternal blood supplies to the membranes and the fetus itself were intact. In the second preparation, the maternal circulation to the membranes and the fetus was intact but the fetal circulation to the membranes was interrupted. In the third preparation, only the maternal circulation to the membranes was intact, the fetus and the fetal circulation to the membranes having been eliminated as possible routes of water exchange.

The procedure for the estimation of water exchange in all three preparations was similar. The jugular vein and carotid artery were exposed and cannulated. The abdomen was opened and a conceptus prepared as required.
Control samples of blood from the carotid artery and of amniotic fluid from an adjacent conceptus were obtained. Then, 9 to $10 \mathrm{ml}$. of deuterium oxide ( 97 to 99.5 per cent) with 0.85 per cent $\mathrm{NaCl}$ were injected rapidly into the
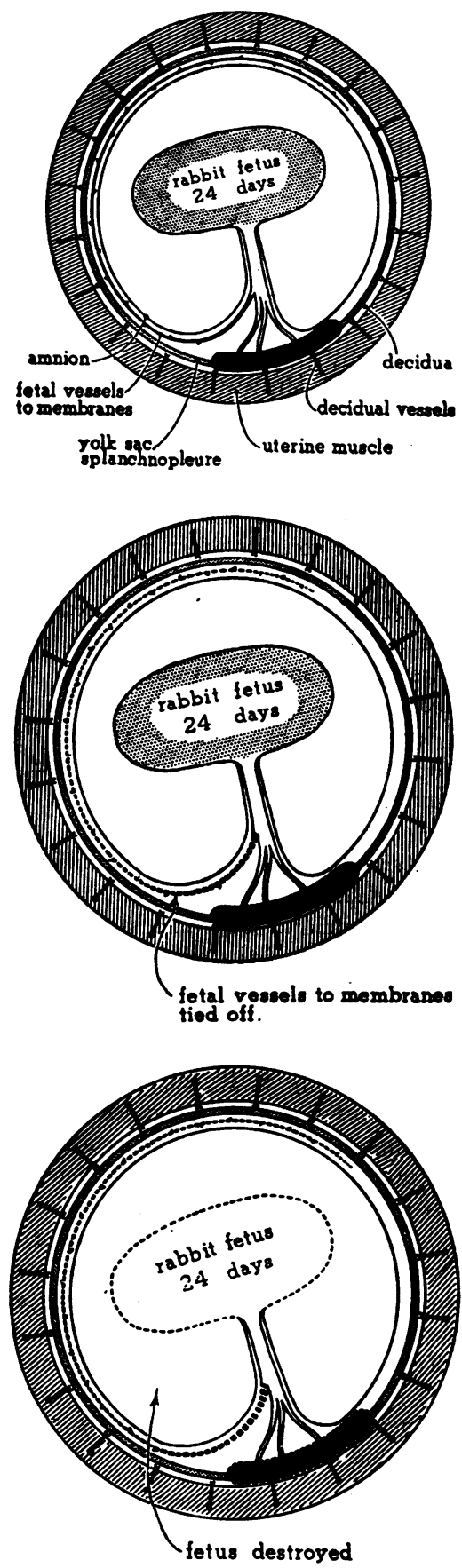

Fig. 1. Schematic Representation of the Rabitt Fetal System with the Membranes and Their Blood Supply. (a). Normal Conceptus. (b). Fetal Vessels to the Membranes Ligated. (c). Fetus Killed. 


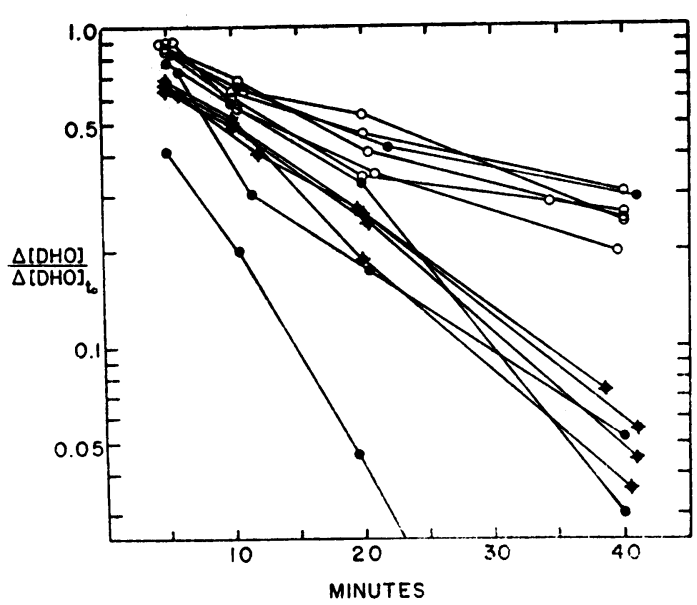

Fig. 2. Deuterium Studies

Ordinates: $\triangle[D H O]$ is the difference between the concentration of DHO in maternal arterial blood ([DHO $]^{\prime \prime}$ ) and the concentration of DHO in amniotic fluid $\left([\mathrm{DHO}]^{\prime}\right) ; \Delta\left[\mathrm{DHO}_{\text {to }}\right.$ is the value of this difference calculated, by linear extrapolation in a semi-logarithmic plot, to obtain at the time of injection. The values of the ratio $\Delta[D H O] / \Delta[D H O]_{t_{0}}$ have been adjusted to unity at time zero. Abscissae: time in minutes after injection. The dots represent values from experiments with the fetus and vitelline vessels intact; the crossed dots, with fetus intact but vitelline vessels ligated; the circles, with fetus crushed. The lines connect the points of a given experiment.

jugular vein; simultaneously 2.0 to 2.5 millicuries of tritium oxide with 0.85 per cent $\mathrm{NaCl}(0.1$ to $0.2 \mathrm{ml}$.) were injected into the amniotic sac. The sac was massaged to mix the contents. (Preliminary observations with dyes showed that this produced almost immediate mixing of the injected material.) Samples of blood from the carotid artery and fluid from the amniotic sac were obtained at approximately 5, 10,20, and 40 minutes after injection. It was found that the most effective method of sampling amniotic fluid was to make a 2 to $3 \mathrm{~mm}$. incision in the uterine wall, allow a small bleb of fluid contained by its membranes to protrude, and tie the bleb off with a previously prepared purse string suture. The fluid in the bleb was then aspirated directly into small caliber pyrex tubing drawn to capillary size at one end. ${ }^{5}$ The sample tubes were sealed immediately and stored for analysis. The condition of the fetus was checked with care in those preparations requiring a living fetus. Only those experiments in which the animals showed lively fetuses with rapid heart rates at the conclusion of the

6 The manipulations required by the sampling procedure apparently ensured adequate mixing. This was demonstrated by the injection of a dye into the amniotic sac; rapid mixing throughout the sac occurred in a few seconds. If mixing had not been adequate, the rate coefficients calculated from the deuterium data and from the tritium data could not have been so nearly identical. experiment are included here. If there was doubt about the state of the fetal circulation during the period of exchange, the experiment was discarded.

For methods used in determination of tritium and deuterium see (14) and (15). The volume of amniotic fluid was measured in graduated cylinders to the nearest tenth $\mathrm{ml}$. at the end of each experiment.

\section{Assumptions and calculations}

The equations commonly used for exchange rate calculations are based on analogies with radioactive decay processes (16). However, the equations can be derived by simplification of a thermodynamic relationship as follows.

The fundamental assumption used (see 17) is that the amount, $S_{J}$, of any substance, $J$, crossing the maternal blood-amniotic fluid barrier per unit time, $t$, is proportional to the product of the concentration of $\mathrm{J},[\mathrm{J}]$, on that side of the barrier where its chemical potential is highest, the gradient of the chemical potential of $\mathrm{J}, \mathrm{d} \mu \mathrm{J} / \mathrm{dx}$, and the area, $A_{J}$, across which passage takes place. This assumption may be expressed as follows:

$$
\mathrm{dS}_{\mathrm{J}} / \mathrm{dt}=-\mathrm{A}_{\mathbf{J}} \cdot \mathrm{K}_{\mathrm{J}} \cdot[\mathrm{J}] \cdot \mathrm{d}_{\mu_{\mathrm{J}}} / \mathrm{dx}
$$

$\mathrm{K}_{\mathrm{J}}$ is the proportionality coefficient and has the dimensions of a mobility. For the non-ionic isotopic compounds, DHO and THO, considered here we have:

$$
\mathrm{d}_{\mu \mathrm{J}} / \mathrm{dx}=\overline{\mathrm{V}}_{\mathrm{J}} \cdot \mathrm{dP} / \mathrm{dx}+\mathrm{RT} \cdot \mathrm{d} \ln \mathrm{aJ}_{\mathrm{J}} / \mathrm{dx},
$$

where $\bar{V}_{J}$ is the partial molal volume of $J, P$ is pressure, $R$ is the gas constant, $T$ is temperature, In denotes natural logarithm, and as denotes the activity of $\mathrm{J}$.

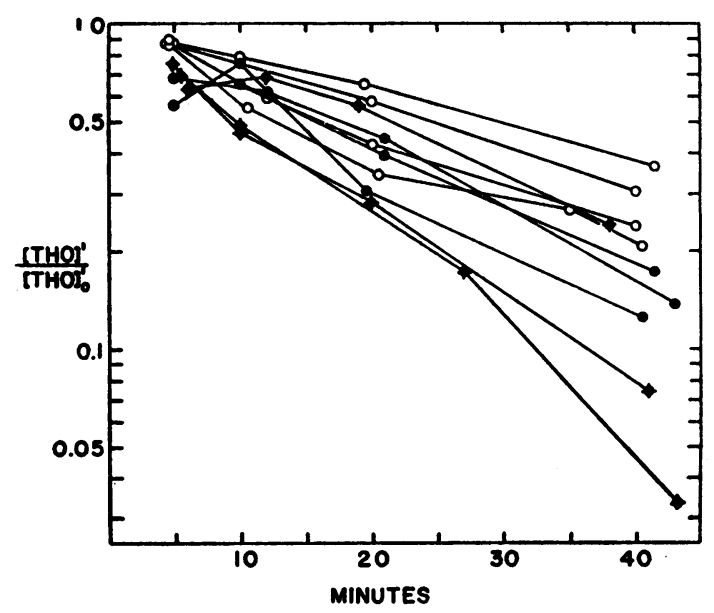

Fig. 3. Tritium Studies

Ordinates: concentration found in amniotic fluid divided by concentration calculated for amniotic fluid at zero time. Abscissae: time in minutes after injection. The dots represent values from experiments with the fetus and the vitelline vessels intact; the crossed dots, with fetus intact but vitelline vessels tied; the circles, with fetus crushed. The lines connect the points of a given experiment. 
In the present experiments $\bar{V}_{J} \cdot d P / d x$ is considered to be negligibly small compared to $R T \cdot d \ln a_{J} / d x$. In addition, because of the very small concentrations at which the isotopic compounds are used, the activity coefficients are assumed to be unity and accordingly concentrations are substituted for activities. The last term of (2) becomes $\frac{\mathrm{RT}}{[\mathrm{J}]} \cdot \mathrm{d}[\mathrm{J}] / \mathrm{dx}$ and on substitution of this for $\mathrm{d} \mu \mathrm{J} / \mathrm{dx}$ in $(1)$ there is obtained:

$$
\mathrm{dS}_{\mathrm{J}} / \mathrm{dt}=-\mathrm{A}_{\mathrm{J}} \cdot \mathrm{K}_{\mathrm{J}} \cdot \mathrm{RT} \cdot \mathrm{d}[\mathrm{J}] / \mathrm{dx} .
$$

For linear gradients $\mathrm{d}[\mathrm{J}] / \mathrm{dx}$ may be replaced by $\frac{\left([\mathrm{J}]^{\prime \prime}-[\mathrm{J}]^{\prime}\right)}{\Delta \mathrm{x}}$ where the double primes denote the maternal side and the single primes the amniotic fluid side of the barrier which has a thickness $\Delta x$. Expression (3) then becomes:

$$
\mathrm{dS}_{\mathrm{J}}{ }^{\prime \prime} / \mathrm{dt}=-\mathrm{kJ}_{\mathrm{J}} \cdot\left([\mathrm{J}]^{\prime \prime}-[\mathrm{J}]^{\prime}\right),
$$

where $\mathrm{k}_{\mathrm{J}}=\mathrm{A}_{\mathrm{J}} \cdot \mathrm{K}_{\mathrm{J}} \cdot \mathrm{RT} / \Delta \mathrm{x}$. Expression (4) is similar to the basic expressions used in (18) and (19). From (4) there is obtained (see References $3,4,18$ ) the following expression for the passage of DHO from the maternal arterial blood to amniotic fluid:

$$
\begin{aligned}
& \ln \frac{[\mathrm{DHO}]^{\prime \prime}-[\mathrm{DHO}]^{\prime}}{[\mathrm{DHO}]_{0}^{\prime \prime}} \\
& \quad=-\mathrm{k}_{\mathrm{DHO}} \cdot \mathrm{t} \cdot\left(1 / \mathrm{V}_{1}+1 / \mathrm{V}_{2}\right)=-\frac{0.693 \mathrm{t}}{\mathrm{T}_{1}}
\end{aligned}
$$

$V_{1}$ is the volume of total maternal water, $V_{2}$ is the volume of amniotic fluid, and $\mathrm{T}_{\mathbf{1}}$ is the time at which ([DHO $]^{\prime \prime}$ $\left.-[\mathrm{DHO}]^{\prime}\right) /[\mathrm{DHO}]_{0}^{\prime \prime}$ has the value 0.5. [DHO $]_{0}^{\prime \prime}$ is the value of $[\mathrm{DHO}]^{\prime \prime}$ that would have obtained at time zero had the distribution of DHO been instantaneously uniform. In these experiments $1 / \mathrm{V}_{1}$ was negligibly small compared to $1 / \mathrm{V}_{2} ; \mathrm{V}_{1}$ was between 1,700 and $2,800 \mathrm{ml}$. and $V_{2}$ was between 2.8 and $4.5 \mathrm{ml}$. Accordingly, no significant error would be introduced by the assumption that $[\mathrm{DHO}]_{0}^{\prime \prime}$ and $[\mathrm{DHO}]^{\prime \prime}$ at infinite time, i.e., at equilibrium, were identical. It was noted that the rate of change of the concentration of DHO in blood after 35 minutes was negligibly small; [DHO $]_{40}^{\prime \prime}$, the concentration at 40 minutes, would therefore differ but slightly from

\begin{tabular}{|c|c|c|c|c|c|}
\hline \multirow[b]{2}{*}{$\begin{array}{l}\text { Expt. } \\
\text { No. }\end{array}$} & \multicolumn{2}{|c|}{$T_{1}$} & \multirow[b]{2}{*}{$\underset{(m l .)}{\mathrm{V}_{2}}$} & \multicolumn{2}{|c|}{$-\mathrm{k}$} \\
\hline & $\begin{array}{l}\text { Deuterium } \\
(\min .)\end{array}$ & $\underset{(\min .)}{\text { Tritium }}$ & & $\begin{array}{l}\text { Deuterium } \\
(m l . / \min .)\end{array}$ & $\underset{(m l . / m i n .)}{\text { Tritium }}$ \\
\hline \multicolumn{6}{|c|}{ Fetus and vitelline vessels intact } \\
\hline$\stackrel{\substack{\mathrm{B} \\
\mathrm{C} \\
\mathrm{J} \\
\text { Mean }}}{ }$ & $\begin{array}{c}17 \\
5 \\
12 \\
8 \\
10.5\end{array}$ & $\begin{array}{r}16 \\
7 \\
14 \\
12.3\end{array}$ & $\begin{array}{l}4.0 \\
3.9 \\
3.3 \\
4.3 \\
3.88\end{array}$ & $\begin{array}{l}.16 \\
.54 \\
.19 \\
.37 \\
.315\end{array}$ & $\begin{array}{l}.17 \\
.37 \\
.16 \\
.233\end{array}$ \\
\hline \multicolumn{6}{|c|}{ Fetus intact but vitelline vessels tied } \\
\hline $\begin{array}{c}\mathrm{G} \\
\mathrm{I} \\
\mathrm{M} \\
\mathrm{T} \\
\text { Mean }\end{array}$ & $\begin{array}{l}10 \\
10 \\
11 \\
12 \\
10.8\end{array}$ & $\begin{array}{l}11 \\
10 \\
16 \\
12.3\end{array}$ & $\begin{array}{l}4.5 \\
3.4 \\
3.2 \\
4.0 \\
3.78\end{array}$ & $\begin{array}{l}.31 \\
.24 \\
.21 \\
.24 \\
.250\end{array}$ & $\begin{array}{l}.28 \\
.24 \\
.17 \\
.230\end{array}$ \\
\hline \multicolumn{6}{|c|}{ All experiments with fetus intact } \\
\hline $\begin{array}{l}\text { Mean } \\
\text { s.d. }\end{array}$ & $\begin{array}{r}10.6 \\
3.5\end{array}$ & $\begin{array}{r}12.3 \\
4.1\end{array}$ & $\begin{array}{l}3.83 \\
0.48\end{array}$ & $\begin{array}{l}.283 \\
.128\end{array}$ & $\begin{array}{l}.232 \\
.082\end{array}$ \\
\hline \multicolumn{6}{|c|}{ Fetus crushed } \\
\hline $\begin{array}{l}\mathrm{E} \\
\mathbf{F} \\
\mathbf{N} \\
\mathrm{P} \\
\mathrm{S} \\
\text { Mean } \\
\text { s.d. }\end{array}$ & $\begin{array}{l}19 \\
20 \\
22 \\
20 \\
20 \\
20.2 \\
1.1\end{array}$ & $\begin{array}{l}17 \\
27 \\
\\
23 \\
18 \\
21.3 \\
4.7\end{array}$ & $\begin{array}{l}2.8 \\
3.3 \\
3.0 \\
3.8 \\
3.6 \\
3.30 \\
0.41\end{array}$ & $\begin{array}{l}.10 \\
.12 \\
.10 \\
.13 \\
.13 \\
.116 \\
.014\end{array}$ & $\begin{array}{l}.11 \\
.09 \\
.12 \\
.14 \\
.115 \\
.022\end{array}$ \\
\hline $\mathrm{P}$ & $<.01$ & $<.01$ & $<.10$ & $<.01$ & $<.05$ \\
\hline
\end{tabular}
$[\mathrm{DHO}]^{\prime \prime}$ at infinite time. Accordingly, the following

TABLE I

Summary of data and calculations*

* s.d. denotes standard deviation; $P$ is the probability, by the " $t$ " test, that the differences of the appropriate means of all the experiments with the fetus intact and of the experiments with the fetus crushed could or:cur by chance. For other symbols, see text. 
working expression was used for the calculation of the values of $\mathrm{kpHo}$ :

$$
\ln \frac{[\mathrm{DHO}]^{\prime \prime}-[\mathrm{DHO}]^{\prime}}{[\mathrm{DHO}]_{40}^{\prime \prime}}=-\frac{\mathrm{k}_{\mathrm{DHO}} \cdot \mathrm{t}}{V_{2}}=-\frac{0.693 \mathrm{t}}{T_{3}} .
$$

In the tritium experiments it was found that all the values for [THO $]^{\prime \prime}$ were less than 7 per cent of the corresponding values of [THO ]' (most were less than 1 per cent). Accordingly, for the tritium data the working expression used was:

$$
\ln \frac{[\mathrm{THO}]}{[\mathrm{THO}]_{0}^{\prime}}=-\frac{\mathrm{k}_{\mathrm{THO}} \cdot \mathrm{t}}{\mathrm{V}_{2}}=-\frac{0.693 \mathrm{t}}{\mathrm{T}_{3}}
$$

where [THO $]_{0}^{\prime}$ is the concentration of tritium that would have obtained had mixing in the amniotic fluid been instantaneous. $^{6}$

To calculate values for the rate coefficients from the deuterium data, values for $\left([\mathrm{DHO}]^{\prime \prime}-[\mathrm{DHO}]^{\prime}\right) /[\mathrm{DHO}]_{40}^{\prime \prime}$ were plotted on a logarithmic scale against time on a linear scale and $T_{\xi}$ was calculated graphically from a visually fitted straight line through the points. For the tritium data, values of $[\mathrm{THO}]^{\prime}$ were plotted on a logarithmic scale against time on a linear scale; a straight line fitted visually to the points was extrapolated to zero time to give $\left[\mathrm{THO}_{0}^{\prime} ; \mathrm{T}_{\frac{1}{2}}\right.$ was then calculated as for deuterium. ${ }^{7}$

It is assumed in these formulations that the distribution of the tracers in each compartment is uniform, that the exchanges take place directly between maternal arterial blood and amniotic fluid, and that there is no significant differential isotope effect in the rates of passage of deuterium and tritium oxides. The first assumption is not valid for deuterium: loss from the blood stream occurs before mixing is complete (see [20]). The second assumption is not valid: as shown below the fetus and the membranes are sites of exchange and an inhomogeneous barrier is interposed between maternal arterial blood and amniotic fluid for part of the exchanges. The third assumption is probably valid (see [15] and [21]). The lack of validity of the first two assumptions reduces the significance of the calculated rates of exchange as absolute values.

\section{RESULTS}

The data for DHO and THO are shown in Figures 2 and 3. Summaries of other data and of the calculations are given in Table I. No significant differences in the values of $T_{1 / 2}, k_{D H O}$, or $\mathrm{k}_{\text {THо }}$ were found for the experiments in which the vitelline vessels were tied and for the experiments in which both the vitelline vessels and the fetus

${ }^{6}$ The minus signs of the right hand terms of equations (5), (6) and (7) do not appear in the derivations in References 3,4 , and 18 .

${ }^{7}$ It is obvious on inspection of Figures 2 and 3, that the fit of straight lines to the experimental points is approximate. Similar lack of fit is evident on inspection of the figures in (3) and (4). It is possible that these deviations are due to irregularities of mixing in the several compartments. were intact. Significant differences were found, however, in the comparison of the values of $T_{1 / 2}$ and the k's for all the experiments in which the fetus was intact with the values for the experiments in which the fetus was crushed. The values of $\mathrm{T}_{1 / 2}$ calculated from the $\mathrm{DHO}$ data and those calculated from the $\mathrm{THO}$ data do not differ significantly within the two groups.

\section{DISCUSSION}

The rate coefficients calculated from the deuterium data and those calculated from the tritium data do not differ significantly in the series of experiments in which the fetus was intact; similarly, in the series of experiments in which the fetus was crushed the mean rate coefficient calculated from the tritium data is identical to the corresponding rate coefficient calculated from the deuterium data. The mean values of the rate coefficients for the experiments in which the fetus was crushed are approximately one-half the mean values for the experiments in which the fetus was left intact. That the values of $T_{1 / 2}$ calculated from the deuterium data and from the tritium data do not differ significantly supports the suggestion that the simplifying assumptions used to permit calculations of the rate coefficients, though not strictly valid, at least are permissible for approximate purposes. It is therefore assumed that the rate coefficients represent rates of exchange of water. These rates of exchange are reduced by one-half in the experiments in which the fetus was crushed. The residual exchanges could not have been taking place at equal rates in both directions across the fetusplacenta complex; they must have been taking place across the membranes. From these findings it is concluded that, in the intact system, half the exchange takes place across the membranes and half takes place across the fetus-placenta complex.

These experiments do not necessarily exclude the possibility that amniotic fluid accumulation is the result of a rate of production of fluid by the fetus slightly greater than the rate of loss across the membranes; however, the rate of net accumulation must be small compared to the rates of exchange. The data do not support the possibility that the maintenance of the relative constancy of amniotic fluid volume is the result of the type of steady state discussed above. However, the hy- 
pothesis that near equilibrium exists with respect to water between the maternal system and the amniotic fluid is compatible with the data.

As to the mechanism involved in the exchange of water across the two major barriers, it appears reasonable to conclude that diffusion is dominant in view of the near equality of the rate coefficients of $\mathrm{DHO}$ and THO. If diffusion is indeed the mechanism of passage values can be calculated for $\Delta x$, the thickness of the barrier, from the data of the experiments in which the fetus was crushed and the relationship $\mathrm{k}_{\mathrm{J}}=\mathrm{A}_{\mathrm{J}} \cdot \mathrm{K}_{\mathrm{J}} \cdot \mathrm{RT} / \Delta \mathrm{x}$. The conventional diffusion coefficient, $\mathrm{D}_{\mathrm{J}}$, is equal to $K_{J} \cdot R T$. A value for $A_{J}$ can be calculated from the volume of amniotic fluid on the assumption that the fluid is contained in a sphere; in the experiments in which the fetus was crushed, $A_{J}$ is approximately $10.7 \mathrm{~cm}^{2}$. For $D_{\mathrm{H}_{2} \mathrm{O}}$ the value $3.4 \times 10^{-5} \mathrm{~cm}^{2}$. $/ \mathrm{sec}$. is used on the assumption that the barrier between maternal capillary blood and amniotic fluid has no effect on the diffusion of water. ${ }^{8}$ The rate coefficient for this group of experiments is $0.12 \mathrm{ml}$. per min. From these values and with these assumptions, the value of $\Delta x$ is found to be $0.2 \mathrm{~cm}$. This virtual value is at least twice the actual thickness; it appears that the barrier impedes the diffusion of water and that the diffusion coefficient of water in the barrier has a value less than that of the self-diffusion coefficient. This restriction to the diffusion of water implies a greater restriction to the diffusion of larger substances. Other investigators $(2,4)$ have reported values for the exchange of sodium between the maternal system and amniotic fluid less than the values for the exchange of water by factors of 3 to 5 . The data of Mills and Adamson (23) suggest that the self-diffusion coefficient of sodium in aqueous solutions is less than the self-diffusion coefficient of water by a factor of not more than 2 . The hy-

\footnotetext{
${ }^{8}$ The value of the self-diffusion coefficient of water is uncertain. The value used above for $\mathrm{D}_{\mathrm{H}_{2} \mathrm{O}}$ at $37^{\circ}$ is interpolated from the DHO and THO data of Wang, Robinson, and Edelman (22); it is less by about 14 per cent than the values reported for $\mathrm{D}_{\mathrm{H}_{2} \mathrm{O}^{18}}$ under similar conditions. The experimental procedure of Wang, Robinson, and Edelman has been criticized recently by Mills and Adamson (23). In vivo experiments show no significant difference in the relative rates of passage of $\mathrm{THO}$ and $\mathrm{H}_{2} \mathrm{O}^{18}$ across pulmonary capillaries in the dog (21). The diffusion coefficients of $\mathrm{H}_{2} \mathrm{O}$, DHO, THO, and $\mathrm{H}_{2} \mathrm{O}^{18}$ probably do not differ by more than 5 per cent.
}

pothesis that diffusion across the barrier is hindered or restricted is in accord with these findings of ratios of exchange rates greater than the ratios of the corresponding self-diffusion coefficients.

As indicated elsewhere (see, for example, 20, 24) diffusion is determined by gradients of chemical potentials (which include the effects of pressure gradients) and not solely by gradients of concentrations. It would be of considerable interest to investigate the pressure relationships between amniotic fluid and uterine interstitial fluid at various stages of pregnancy.

The evidence obtained in other studies (for example, 20, 25) indicates that the sampling techniques used here may not give an accurate neasure of the very rapid exchanges detectable with more rapid sampling; the values calculated for the exchange rates may be underestimates. Properly, samples of uterine vein blood should have been obtained. Further uncertainty concerning the actual rates of exchange arises from the simplifying assumptions used in the calculations. Finally, the fetuses were neither weighed at the end of the experiments nor analyzed for deuterium and tritium. It was not determined whether the fetal system approached the maternal system or amniotic fluid in composition; serial determinations of fetal composition were technically impossible in these studies. In any event, whatever the real values of the rates of exchange, it is evident that these are quite high.

The conclusion that rapid exchange of water occurs across the membranes suggests that other investigations, similar to those presented here, would be warranted. These might include studies of the exchange of sodium, carbon dioxide, urea, and oxygen across this barrier and would thus supplement the studies of trans-placental exchanges of these substances.

\section{SUM M ARY}

A procedure has been devised which permits evaluation of the relative importance of fetus and membranes as sites for exchange for amniotic fluid water in rabbits at the 24th day of gestation.

Rates of exchange of water calculated 1) from the rates of passage of deuterium oxide from the maternal system to amniotic fluid, and 2) from the rates of passage of tritium oxide in the op- 
posite direction are approximately equal at about $0.26 \mathrm{ml}$. per min. with intact fetal systems. When the fetus is crushed these rates of exchange are reduced by approximately one-half to $0.12 \mathrm{ml}$. per min. Ligation of the vitelline vessels produces no significant reduction of the rates.

It is concluded that approximately half the exchange of water occurs across the placenta by way of the placenta and fetus and half occurs across the membranes by way of the maternal circulation and that the vitelline vessels contribute a negligible fraction to the exchange.

The possibility is considered that a steady state with respect to water in the amniotic sac is maintained by secretory activity of the fetus. It is concluded that a steady state does not exist between the maternal system and the amniotic fluid and that equilibrium obtains with respect to water. It is suggested that diffusion is the mechanism of passage of water across the barrier between maternal blood and amniotic fluid and that the barrier provides a significant restriction to free diffusion.

\section{REFERENCES}

1. Flexner, L. B., and Gellhorn, A., The transfer of water and sodium to the amniotic fluid of the guinea pig. Am. J. Physiol., 1942, 136, 757.

2. Vosburgh, G. J., Flexner, L. B., Cowie, D. B., Hellman, L. M., Proctor, N. K., and Wilde, W. S., The rate of renewal in woman of the water and sodium of the amniotic fluid as determined by tracer techniques. Am. J. Obst. \& Gynec., 1948, 56, 1156.

3. Plentl, A. A., and Hutchinson, D. L., Determination of deuterium exchange rates between maternal circulation and amniotic fluid. Proc. Soc. Exper. Biol. \& Med., 1953, 82, 681.

4. Neslen, E. D., Hunter, C. B., and Plentl, A. A., Rate of exchange of sodium and potassium between amniotic fluid and maternal system. Proc. Soc. Exper. Biol. \& Med., 1954, 86, 432.

5. Needham, J., Chemical Embryology. Vol. 3. Cambridge, Cambridge University Press, 1931.

6. Bernstine, J. B., and Meyer, A. E., Passage of metabolites of chloral hydrate into amniotic fluid. Proc. Soc. Exper. Biol. \& Med., 1953, 84, 456.

7. McCance, R. A., and Widdowson, E. M., Water metabolism. Cold Spring Harbor Symp. Quant. Biol., 1954, 19, 155.

8. Dawes, G. S., Discussion. Cold Spring Harbor Symp. Quant. Biol., 1954, 19, 164.

9. Jost, A., Discussion. Cold Spring Harbor Symp. Quant. Biol., 1954, 19, 164.
10. Reynolds, S. R. M., A source of amniotic fluid in the lamb: the naso-pharyngeal and buccal cavities. Nature, 1953, 172, 307.

11. Brambell, F. W. R., Transport of proteins across the fetal membranes. Cold Spring Harbor Symp. Quant. Biol., 1954, 19, 71.

12. Hammond, J., Changes in the reproductive organs of the rabbit during pregnancy in Transactions on the Dynamics of Development, Moscow, Instit Zhivotnovodstva, Trudy no Dinamike Razvitiia., 1935, 10, 93.

13. Brambell, F. W. R., Hemmings, G. P., Hemmings, W. A., Henderson, M., and Rowlands, W. T., The route by which antibodies enter the circulation after injection of immune serum into the exocoel of foetal rabbits. Proc. Roy. Soc., London, s.B., 1951, 138, 188.

14. Chinard, F. P., and Enns, T., Preparation of water samples for deuterium analysis in the mass spectrometer. Anal. Chem., 1953, 25, 1413.

15. Chinard, F. P., and Enns, T., Relative rates of passage of deuterium and tritium oxides across capillary walls in the dog. Am. J. Physiol., 1954, 178, 203.

16. Hevesy, G., Radioactive indicators. Their application in biochemistry, animal physiology, and pathology. New York, Interscience Publishers, Inc., 1948, p. 251.

17. Chinard, F. P., Derivation of an expression for the rate of formation of glomerular fluid (GFR). Applicability of certain physical and physicochemical concepts. Am. J. Physiol., 1952, 171, 578.

18. Sheppard, C. W., and Householder, A. S., The mathematical basis of the interpretation of tracer experiments in closed steady-state systems. J. Applied Physiol., 1951, 22, 510.

19. Solomon, A. K., Equations for tracer experiments. J. Clin. Invest., 1949, 28, 1297.

20. Chinard, F. P., and Enns, T., Transcapillary pulmonary exchange of water in the dog. Am. J. Physiol., 1954, 178, 197.

21. Enns, T., and Chinard, F. P., Relative rates of passage of $\mathrm{H}^{1} \mathrm{H}^{3} \mathrm{O}^{16}$ and of $\mathrm{H}_{2}^{1} \mathrm{O}^{18}$ across pulmonary vessels in the dog. Am. J. Physiol., In press.

22. Wang, J. H., Robinson, C. V., and Edelman, I. S., Self-diffusion and structure of liquid water. III. Measurement of the self-diffusion of liquid water with $\mathrm{H}^{2}, \mathrm{H}^{3}$ and $\mathrm{O}^{18}$ as tracers. J. Am. Chem. Soc., 1953, 75, 466.

23. Mills, R., and Adamson, A. W., The measurement of self-diffusion in electrolyte solutions. J. Am. Chem. Soc., 1955, 77, 3454.

24. Chinard, F. P., Biochemical evaluation. Cold Spring Harbor Symp. Quant. Biol., 1954, 19, 209.

25. Chinard, F. P., Vosburgh, G. J., and Enns, T., Transcapillary exchange of water and of other substances in certain organs of the dog. Am. J. Physiol., 1955, 183, 221. 